\title{
Cerebral aneurysms associated with von Recklinghausen's neurofibromatosis: Report of a case and review of the literature
}

\author{
J. Baldauf, J. Kiwit, M. Synowitz \\ Department of Neurosurgery, Helios Hospital Berlin, Berlin, Germany
}

The authors report a case of an intracranial aneurysm associated with von Recklinghausen's neurofibromatosis. A 34year-old woman presented with a history of headaches, unconsciousness and neck rigidity. Widespread cutaneous neurofibromas were found. Investigations revealed an aneurysm of the anterior communicating artery. The authors discuss this case and review the relevant literature.

Key Words: Intracranial aneurysm, neurofibromatosis-1

von Recklinghausen's neurofibromatosis type I (vRNF) is an autosomal dominant disorder caused by mutations in the neurofibromatosis-1 (NF-1) gene on chromosome 17. This hereditable systemic disease affects approximately 1 in 3500 individuals. ${ }^{[1]}$ Typical dysplasias in NF-1 patients involve the skeletal system (sphenoid wing dysplasia, tibial pseudarthrosis), the skin (café-au-lait spots), and the nervous system (optic pathway gliomas, neurofibromas, astrocytomas, meningeomas). Vascular abnormalities are well recognized in NF-1 and seen in the renal, gastrointestinal and coronary vessels. ${ }^{[2-5]}$ Cerebral vascular manifestations include stenosis or occlusion of major vessels, AV-fistulae, arteriovenous malformations, and aneurysms. ${ }^{[6]}$ Pathological changes in vessels in NF-1, in some cases, have radiographic similarities to moyamoya disease and intracranial aneurysms are mostly saccular or fusiform. ${ }^{[7]}$ We report a case of vRNF associated with an intracranial aneurysm and compare it to similar cases found in the literature.

\section{Case Report}

A 34-year-old right-handed female with known vRNF presented with a history of sudden onset of headaches, unconsciousness and neck rigidity. Physical examination revealed that there were neurofibromas and café-au-lait spots distributed over the entire body. There was Grade 4 right hemiparesis, left-sided protrusio bulbi combined with a chemosis of the conjunctiva and loss of vision [Figure 1].

The patient had no family history of NF-1. An additional molecular diagnosis of the NF-1 gene was not performed at our clinic. A cranial computerized tomography (CCT) scan and magnetic resonance images (MRI) of the brain revealed diffuse subarachnoid hemorrhage (SAH) predominantly in the basal cisterns as well as in the left parietal region with an intraventricular hemorrhage (Fisher Kissler Grade 4). Additionally, a left intraorbital mass was recognized. Digital subtraction angiography (DSA) demonstrated an aneurysm of the anterior communicating artery (A-com) [Figure 2].

The aneurysm was clipped via a right peritoneal approach and the intraorbital tumor on the left side was removed with orbital bony wall decompression via a left frontal approach on the same session. Neuropathological/immunohistological examination verified the tumor as an orbital neurofibroma. After 3 and 6 months follow up, significant improvement in consciousness and mental deterioration was seen.

\section{Discussion}

Intracranial aneurysms are rare in cases with NF-1. Including our case, we identified 28 cases of intracranial aneurysms in the literature [Table 1]. Predominantly, the aneurysms were

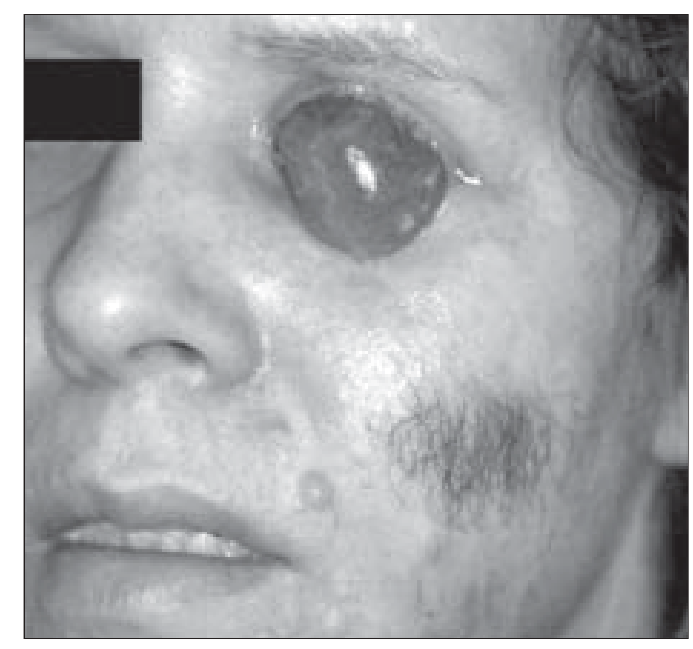

Figure 1: Orbital neurofibroma in neurofibromatosis Type 1 


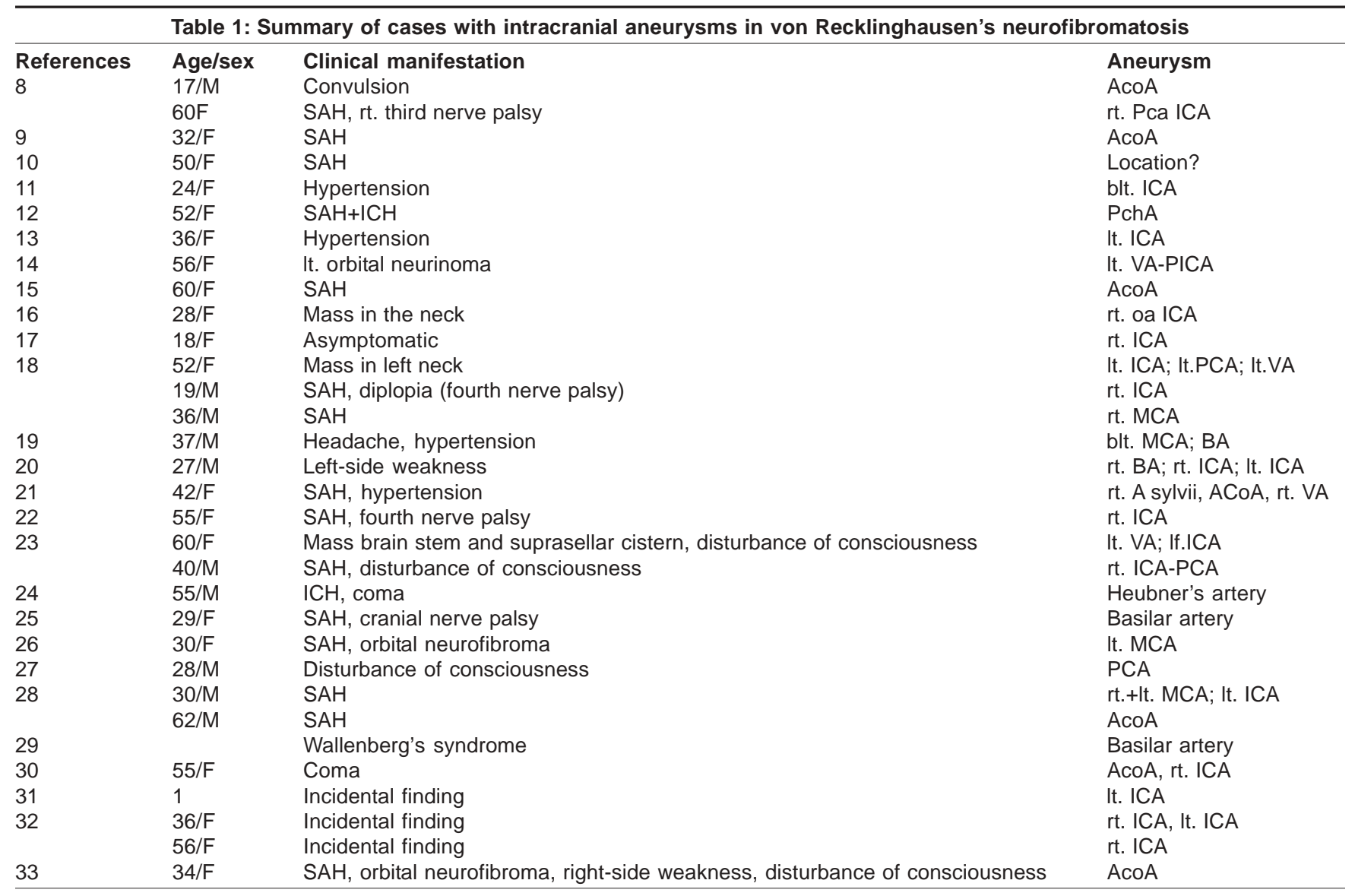

F, female; M, male; ICA, internal carotid artery; MCA, middle cerebral artery; VA, vertebral artery; PCA, posterior cerebral artery; AcoA, anterior communicating artery; pcalCA, ICA at posterior communicating artery origin; VA-PICA, VA at posterior inferior cerebellar artery origin; PChA, posterior choroidal artery; oalCA, ICA at ophthalmic artery origin; ICH, intracerebral haematoma; SAH, subarachnoid hemorrhage; rt, right; It, left; blt, bilateral.

located in the ICA circulation. In three cases, the aneurysms was in the vertebrobasilar circulation, and eight patients had multiple aneurysms. ${ }^{[12,34]}$ A female predominance could be observed. ${ }^{[34,35]}$

The pathogenesis of vascular abnormalities in neurofibromatosis is unclear. Intracranial aneurysms in NF-1 might occur

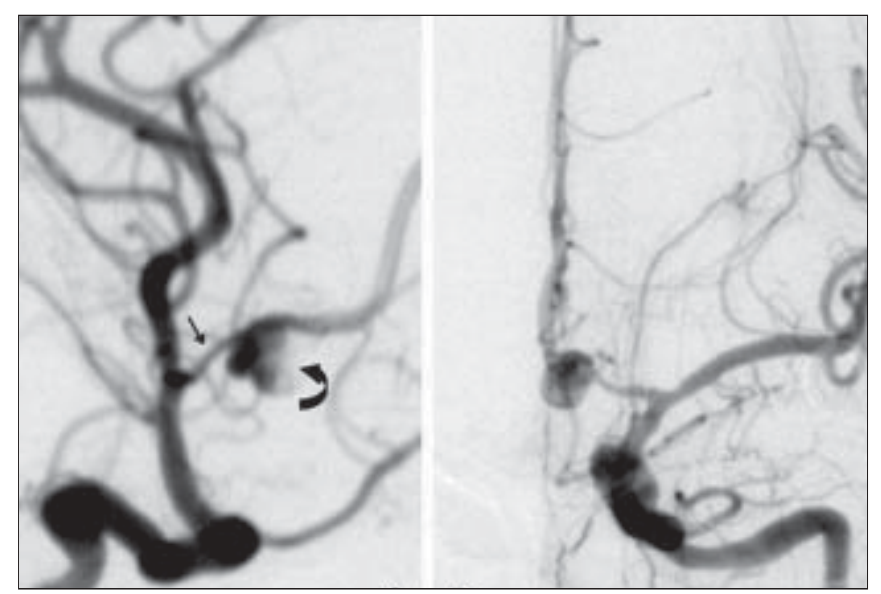

Figure 2: Lateral and anteroposterior views of the left internal carotid angiography (ICAG) showing a multilobulated aneurysm of the anterior communicating artery (curved arrow) and a vasospasm of this artery (straight arrow) as a result of the radiation therapy of gliomas of the optic chiasm. ${ }^{[21]}$ The first histological studies of vascular lesions in vRNF were done by Reubi in $1944 .{ }^{[36]}$ He classified the changes in the arterial walls depending on their diameter (50-400 pm, 100-700 pm, 0.5-1 mm) into three groups: pure intimal form, nodular form, and intimal aneurysm form. At least the intimal aneurysm form was typical for cerebral aneurysms and had marked, eccentric, fibrous intimal proliferation, a small number of sparsely distributed spindle cells in the intima and media, smooth muscle fibrosis, and elastica fragmentation. Other reports by Feylter et al added new or similar features of histological changes including irregular smooth muscle loss or nodular proliferation of epitheloid and spindle cells. ${ }^{[34,37]}$ Using electron microscopy studies, Greene et al. found that the spindle cells had characteristics of smooth muscle cells, with myofilaments, pinocytotic vessels, and electron dense plaques associated with the plasma membrane and free within the cytoplasm. ${ }^{[3]}$

There seems to be no link for a neural cause of vessel malformations in NF-1. Changes in the walls of vessels may depend on primary defects of myocytes inside these walls, and probably pericytes play an important role. ${ }^{[35]}$

New publications asked for the expression of the NF-1 gene product neurofibromin and its association with blood ves- 
sels. ${ }^{[26,38-40]}$ Neurofibromin is believed to have a regulatory role in the development of various connective tissues. ${ }^{[1]}$ Norton et al demonstrated by immunochemical studies the expression of NF-1 in the endothelial cell layer of rat and bovine renal and cerebral arteries as well as in the aorta. ${ }^{[40]}$ In addition, Western blotting confirmed neurofibromin expression in bovine aorta and cerebral blood vessels. To follow the role of neurofibromin as a negative growth regulator (tumor suppressor gene), Norton concluded that in individuals with NF-1, it is possible that the loss (or reduction) of neurofibromin expression results in vascular abnormalities. Conway et al analyzed autopsy series of NF-1 and aneurysm patients statistically and found no significant relation between the prevalence of intracranial aneurysms and NF-1. ${ }^{[41]}$ In their own series, they found 25 NF-1 cases in 50000 autopsies. Autopsy revealed an intracranial hemorrhage in four patients $(16 \%)$ without the verification of an aneurysm. Schievink et al. studied 39 patients with NF-1 and detected two patients with associated intracranial aneurysms. ${ }^{[32]}$ They found a significantly higher detection rate of cerebral aneurysms in NF1 than in a population consisting of 526 matched controls. In conclusion, they suggested that there is an increased risk of developing intracranial aneurysms in NF-1 patients. This is in accordance with the work of Rosser et al., who analyzed 353 children with NF-1. ${ }^{[31]}$ Cerebrovascular abnormalities including intracranial aneurysms were found in $2.5 \%$ of the cases. The pathophysiology of the vascular changes is not fully understood and needs to be analyzed on a cellular level in the future.

\section{References}

1. Riceardi VM. Neurofibromatosis: Phenotype, Natural History and Pathogenesis. $2^{\text {nd }}$ Ed. Baltimore: John Hopkins University Press; 1992. p. 1-450.

2. Faggioli GL, Gargiulo M, Bertoni F, Tarantini S, Stella A. Hypertension due to an aneurysm of the left renal artery in a patient with neurofibromatosis. Ann Vase Surg 1992;6:456-9.

3. Greene JF Jr, Fitzwater JE, Burgess J. Arterial lesions associated with neurofibromatosis. Am J Clin Pathol 1974;62:481-7.

4. Tins B, Greaves M, Bowling T. Neurofibromatosis associated with a coronary artery aneurysm. Br J Radiol 2000;73:1219-20.

5. Trevelyan J, Been M, Patel R. Multiple coronary aneurysms in a patient with neurofibromatosis type 1: Case report and intravascular ultrasound of aneurysm. Postgrad Med J 2001;77:45-7.

6. Hoffmann KT, Hosten N, Liebig T, Schwarz K, Felix R. Giant Aneurysm of the vertebral artery in neurofibromatosis type 1: Report of a case and review of the literature. Neuroradiology 1989;40:245-8.

7. Brooks BS, et Gammal T, Adams RJ, Hartlage PL, Smith WB. MR imaging of movamova in neurofibromatosis. A.JNR Am .J Neuroradiol 1987;8:178-9.

8. Bergouignan M. A propos des aneurysmes des arterescerebrales associes a d'autres malformations. Acta Neurol Psychiat Belg 1951;51:529-35.

9. Gibbons JRP, Brookes JPCM. Pheochromocytoma associated with multiple neurofibromatosis and aneurysm of circle of Willis. Br J Clin Pract 1967;21:3602.

10. Momose KJ, New PFJ. Non-atheromatous stenosis and occlusion of the internal carotid artery in its main branches. Am J Roentgenol Radium Ther Nucl Med 1973;118:550-66.

11. Rosenbusch VG, Hoefnagels WHL, Koene RAP, Penn W, Thijssen HOM. Renovaskuläre Hypertension bei Neurofibromatose. Fortschr Geb Rontgenstr Nuklearmed Eroänzungsband 1977;126:218-27.

12. Leone RG, Shatzki SC, Wolpow ER. Neurofibromatosis with extensive intracranial arterial occlusive disease. A.JNR Am J Neuroradiol 1982;3:572-6.

13. Debure C, Fiessinger .JN, Bruneval P, Vuong NP, Cormier .JM, Houssett E.
Lésions artérielles multiples au la maladie de von Recklinghausen: Une observation. Presse Med 1984;13:1776-8.

14. Kamiyama K, Endo S, Horie Y, Koshu K, Takaku A. Neurofibromatosis associated with intra- and extracranial aneurysms and extracranial vertebral arteriovenous fistula. No Shinkei Geka 1085;13:875-80

15. Chono Y, Ueno K, Numomura M, Ohta Y, Nomura M, Nakamura, N. VonRecklinghausen's disease associated with occlusion of bilateral middle cerebral artery, moyamoya phenomenon, and an anterior communicating artery aneurysm. Neurol Med Chir 1985;25:209-14.

16. Sobata E, Ohkuma H, Suzuki S. Cerebrovascular disorders associated with von Recklinghausen's neurofibromatosis: a case report. Neurosurgery 1988;22:544-9.

17. Frank E, Brown BM, Wilson DF. Asymptomatic fusiform aneurysm of the petrous carotid artery in a patient with von Recklinghausen's neurofibromatosis. Surg Neurol 1989;32:75-8

18. Muhonen MG, Godersky JC, Van Gilder JC. Cerebral aneurysms associated with neurofibromatosis. Surg Neurol 1991;36:470-5.

19. Gomori JM, Weinberger G, Shachar E, Freilich G. Multiple intracranial aneurysms and neurofibromatosis: A case report. Australas Radiol 1991;35:271-3.

20. Benatar MG. Intracranial fusiform aneurysms in von Recklinghausen's disease: Case report and literature review. J Neurol Neurosurg Psvchiatry $1994 ; 57: 1279-80$

21. Poli P, Peillon C, Ladha E, Watelet J, Testart J. Anéurysmes intracraniens multiples en rapport avec une maladie de Recklinghausen. .J Mal Vase $1994 ; 19: 253-5$.

22. Zhao JZ, Han XD. Cerebral aneurysm associated with von Recklinghausen's neurofibromatosis: A case report. Suro Neurol 1998;50:592-6.

23. Uranishi R, Ochiai C, Okuno S, Nagai M. Cerebral aneurysms associated with von Recklinghausen neurofibromatosis: Report of two cases. No Shinkei Geka $1995 ; 23: 237-42$.

24. Sasaki J, Miura S, Ohishi H, Kikuchi K. Neurofibromatosis associated with multiple intracranial vascular lesions: Stenosis of the internal carotid artery and peripheral aneurysm of the Heubner's artery; report of a case. No Shinkei Geka 1995;23:813-7.

25. Kirchhof K, Vogt-Schaden M, Forsting M. Fusiformes Basilarisaneurysma bei Morbus Recklinghausen. Rofo Fortschr Geb Rontgenstr Neuen Bildgeb Verfahr 1996;165:412-4.

26. Schievink WI. Genetics of intracranial aneurysms. Neurosurgery 1997;40:65162 .

27. Siqueira Neto .JI, Silva GS, De Castro .JD, Santos AC. Neurofibromatosis associated with moyamoya arteriopathy and fusiform aneurysm: case report. Arc Neuropsiquiatr 1998;56:819-23.

28. Oyama H, Nakane T, Handa T, Mizutani N, Ikeda K et al. Two cases of subarachnoid hemorrhage associated with neurofibromatosis type I: a case of multiple cerebral aneurysms and arteriovenous malformation, and another case of an anterior communicating artery aneurysm. No Shinkei Geka 1998·26:151-6.

29. Mitsui Y, Nakasaka Y, Akamatsu M, Ueda H, Kihara M, Takahashi M. Neurfibromatosis type 1 with basilar artery fusiform aneurysm manifesting Wallenberg's svndrome. Intern Med 2001;40:948-51.

30. Fujimoto M, Nakahara I, Tanaka M, Iwamuro Y, Watanabe Y, Harada K. Multiple intracranial aneurysms and vascular abnormalities associated with neurofibromatosis type 1: A case report. No Shinkei Geka 2004;32:355-9.

31. Rosser TL, Vezina G, Packer RJ. Cerebrovascular abnormalities in a population of children with neurofibromatosis type 1. Neurology 2005;64:553-5.

32. Schievink WI, Riedinger M, Marcel Maya M. Frequency of incidental intracranial aneurysms in neurofibromatosis type 1. Am J Med Genet A 2005; Feb 2 , [Epub ahead of print].

33. Authors, 2005.

34. Salyer WR, Salyer DC. The vascular lesions of neuro-fibromatosis. Angiology $1974 ; 25: 510-9$

35. Lassmann G. Vascular dysplasia of arteries inneurocristopathies: A lesson for neurofibromatosis. Neurofibromatosis 1998;1:281-93.

36. Reubi F. Neurofibromatose et lésions vasculaires. Schweiz Med Wochenschr $1944 ; 75: 463-5$.

37. Feylter F. Über die vasculäre Neurofibromatose, nach Untersuchungen am menschlichen Magen-Darmschlauch. Virchows Arch 1949;317:221-65.

38. Hamilton S.J, Friedmann JM. Insights into the pathogenesis of neurofibromatosis 1 vasculopathy. Clin Genet 2000;58:341-4

39. Nekrysh SY. Association between heritable connective tissue disorders and intracranial aneurysms. Surg Neurol 2000;54:77-8

40. Norton KK, Xu .J, Gutmann DH. Expression of the neurofibromatosis I gene product, neurofibromin, in blood vessel endothelial cells and smooth muscle. Neurobiol Dis 1995;2:13-21

41. Conway .JE, Hutchins GM, Tamargo R.J. Lack of evidence for an association between neurofibromatosis type I and intracranial aneurysms: autopsy study and review of the literature. Stroke 2001;32:2481-5.

Accepted on 08-03-2005 